\title{
Primary Care Patients' Willingness to Participate in Comprehensive Weight Loss Programs: From the WWAMI Region Practice and Research Network
}

\author{
Allison M. Cole, MD, MPH, Gina A. Keppel, MPH, Holly A. Andrilla, MS, \\ Carie M. Cox, PhD, Laura-Mae Baldwin, MD, MPH, \\ The WWAMI (Washington, Wyoming, Alaska, Montana, and Idabo) Region Practice \\ and Research Network (WPRN) Patient Preferences for Weight Loss in Primary \\ Care Development Group, and The WPRN Practice Champions
}

Purpose: In the United States, 69\% of adults are overweight or obese, as defined by a body mass index (BMI) $\geq 25 \mathrm{~kg} / \mathrm{m}^{2}$. The US Preventive Services Task Force recommends screening all adult patients for obesity and referring obese patients to intensive, multicomponent behavioral weight loss programs comprising 12 to 26 yearly sessions. The objective of this study is to determine the degree to which overweight and obese primary care patients report willingness to participate in these intensive weight loss programs and to identify the patient factors associated with reported willingness to participate.

Methods: This 2013 cross-sectional survey was offered to all adult patients seen for an office visit at 1 of 12 primary care clinics in the Washington, Wyoming, Alaska, Montana and Idaho (WWAMI) Region Practice and Research Network (WPRN). Patients self-reported both their health information and their willingness to participate in a comprehensive weight loss program. Respondents were characterized by descriptive statistics. We compared reported rates of willingness to participate by patient factors and assessed which patient factors were independently associated with reported willingness using bivariate analysis and logistic regression, respectively.

Results: of overweight and obese respondents, $63 \%$ reported willingness to participate in comprehensive weight loss programs. Age, sex, race/ethnicity, insurance status, BMI, and reason for wanting to lose weight were all significantly and independently associated with reported willingness to participate.

Conclusions: Reported willingness to participate in comprehensive weight loss programs suggests that additional resources are needed to understand strategies for disseminating and implementing effective comprehensive weight loss programs. (J Am Board Fam Med 2016;29:572-580.)

Keywords: Body Mass Index, Cross-Sectional Studies, Ethnic Groups, Evidence-based Medicine, Insurance Coverage, Obesity, Office Visits, Overweight, Practice-based Research, Primary Health Care, Self Report, Weight Reduction

Among adults in the United States, there is a combined prevalence of overweight (body mass index $[\mathrm{BMI}]$ between 25 and $29.9 \mathrm{~kg} / \mathrm{m}^{2}$ ) and obesity

This article was externally peer reviewed.

Submitted 27 January 2016; revised 9 May 2016; accepted 16 May 2016.

From the Department of Family Medicine, University of Washington, Seattle, WA (AMC, GAK, HAA, L-MB); the Institute of Translational Health Sciences, Seattle, WA (AMC, GAK, L-MB); and Public Health and Global Health, St. Catherine University, St. Paul, MN (CMC).

Funding: This project was supported by the National Center for Advancing Translational Sciences of the National Institutes of Health under award UL1TR000423.
(BMI $\geq 30 \mathrm{~kg} / \mathrm{m}^{2}$ ) of $69 \% .^{1}$ Hispanic and African American populations have particularly high rates of overweight and obesity compared with non-His-

Prior presentation: Part of these results was presented at the North American Primary Care Research Group Annual Meeting, New Orleans, Louisiana, December 3, 2013.

Conflict of interest: none declared.

Disclaimer: The content is solely the responsibility of the authors and does not necessarily represent the official views of the National Institutes of Health.

Corresponding author: Allison M. Cole, MD, MPH, Department of Family Medicine, University of Washington, Box 354696, Seattle, WA 98195-4696 (E-mail: acole2 @u.washington.edu). 
panic white populations in the United States (78\%, $76 \%$, and $67 \%$, respectively). ${ }^{1,2}$

Overweight and obesity are associated with increased risk of developing type 2 diabetes, lower health-related quality of life measures, and increased prevalence of chronic pain conditions and depression. $^{3-8}$ In primary care practice, the prevalence of multiple chronic conditions and the utilization of primary care are significantly higher among overweight and obese patients. ${ }^{9,10}$

Based on a large body of evidence from clinical trials, the US Preventive Services Task Force (USPSTF) recommends that primary care providers screen all adult patients for obesity based on BMI and that clinicians offer or refer obese patients to intensive, multicomponent behavioral interventions. ${ }^{11}$ Multicomponent behavioral interventions (eg, improving nutrition and physical activity through behavioral strategies, addressing barriers to change, self-monitoring, and optimizing the maintenance of lifestyle changes) can lead to an average weight loss of 4 to 7 kg. ${ }^{11,12}$ The most effective behavioral interventions are comprehensive and include 12 to 26 sessions in a year. ${ }^{12-14}$ While USPSTF recommendations are limited to the referral of obese patients, there is evidence that overweight patients, especially those with chronic diseases, may also benefit from participation in weight loss programs. ${ }^{15-17}$ The 2010 Patient Protection and Affordable Care Act mandates that health insurance companies cover, with no cost-sharing, obesity screening and counseling for adults and children, which has the potential to reduce financial barriers to participation in weight loss programs and increase the availability of these services. ${ }^{18,19}$

The objectives of this study are (1) to assess, in a diverse network of primary care practices, the degree to which overweight and obese adults report willingness to participate in a comprehensive weight loss program as recommended by the USPSTF, and (2) to determine the patient characteristics associated with reported willingness to participate. The results of this study can be used to guide the development and implementation of evidence-based weight loss programs in primary care practice.

\section{Methods \\ Setting}

This study was conducted in the Washington, $\mathrm{Wy}_{\mathrm{y}}$ oming, Alaska, Montana, and Idaho (WWAMI) Region Practice and Research Network (WPRN), a network of $>50$ primary care practices across WWAMI. Twelve primary care practices across 5 states volunteered to participate.

\section{Participants}

All adult patients (aged $\geq 18$ years) who presented for a primary care visit at 1 of the participating practices over a 2-week period were eligible to participate. Patients who were pregnant or unable to read English or Spanish were excluded.

\section{Procedures}

Eleven sites collected data in June 2013, and 1 collected data in September 2013. At each site, front desk staff were asked to offer all eligible patients a questionnaire and to request that they complete the questionnaire and return it to a closed collection box in the waiting area to ensure anonymity. The University of Washington's institutional review board reviewed this research protocol and designated it as exempt.

\section{Questionnaire}

The brief booklet-form questionnaire included a total of 14 multiple choice and fill-in-the-blank questions. The questionnaire asked for basic demographics and asked participants to report whether they wanted to lose weight right now (yes/no) and whether they thought their doctor would advise them to lose weight (yes/no). Participants were also asked to record the number 1 reason they wanted to lose weight right now and the number of pounds they wanted to lose.

Willingness to take part in a comprehensive weight loss program was assessed with participants' responses to the question, "Weight loss programs that work best have at least 12 visits (in groups or 1-on-1). These programs help you (1) improve your diet and exercise, (2) decide how much weight to lose, and (3) solve problems that get in your way of losing weight. If your town had a 12-visit weight loss program like this, would you take part in it?" The response options were (1) would not take part, (2) maybe would take part, (3) probably would take part, and (4) very likely would take part.

To identify potential facilitators and barriers to participation in a comprehensive weight loss program, we asked participants to mark the top 3 of 8 potential factors (will help me lose weight, will help me feel better, was recommended by a friend or family member, was recommended by my doctor, 
does not cost me much, is easy to get to, is at a convenient time of day, a friend would go with me) that would help them decide whether to participate.

\section{Variables}

Outcomes

The primary outcome was the proportion of patients who reported willingness to participate (very likely or probably would participate in a comprehensive weight loss program).

\section{Descriptive Variables}

Demographics included patients' self-reported sex, age, insurance status, and race/ethnicity. We categorized patients who reported $>1$ race as "multiple races," which is consistent with procedures used by the US Census Bureau. ${ }^{20}$ Participants also selfreported insurance status. Two independent investigators categorized write-in responses to "other" for race/ethnicity and categorized insurance status into existing categories, if possible, or as "other." We grouped insurance categories by similarity (eg, mixed/likely Medicaid and Medicare/Medicaid were grouped with Medicaid) and recoded the remaining "other" insurance respondents as private insurance because private insurance represented the largest single category of respondents.

We used patient self-reported height and weight to calculate BMI using the standard formula (weight in pounds $\times 703$ )/(height in inches squared). We coded BMI into categories based on those used in clinical care (normal weight, 18.5 to $<25 \mathrm{~kg} / \mathrm{m}^{2}$; overweight, $25-29.9 \mathrm{~kg} / \mathrm{m}^{2}$; obese, $30-39 \mathrm{~kg} / \mathrm{m}^{2}$; extremely obese, $\left.\geq 40 \mathrm{~kg} / \mathrm{m}^{2}\right) .{ }^{21} \mathrm{~Pa}$ tients also self-reported their overall health status as excellent, very good, good, fair, or poor.

Two investigators independently reviewed the free-text responses patients wrote as reasons for wanting to lose weight and developed a set of codes that characterized the majority of responses (Table 1). Initial codes were grouped into related categories, creating 5 final categories: appearance, emotional/ family, physical functioning, medical, and age. Each category was used as a separate variable (yes/no) in the analysis so that the relationships between each reason for weight loss and reported likelihood of participating could be assessed.
Table 1. Codes and Sample Quotes Based for Patients' "Number 1 Reason for Wanting to Lose Weight"

\begin{tabular}{|c|c|c|}
\hline Original Code & Example Quote & $\begin{array}{l}\text { Final Grouped } \\
\text { Code }\end{array}$ \\
\hline Health & "Overall my health" & Physical functioning \\
\hline Medical & "Type 2 diabetes" & Medical \\
\hline Energy & "More energy" & Physical functioning \\
\hline Musculoskeletal & "Hip problems" & Medical \\
\hline Clothes & $\begin{array}{l}\text { "Cannot fit in my } \\
\text { clothes" }\end{array}$ & Appearance \\
\hline Feel better & "Feel better" & Physical functioning \\
\hline Pain & "Lower pain level" & Medical \\
\hline Fitness & "To be more fit" & Physical functioning \\
\hline Emotional & $\begin{array}{l}\text { "I want to feel better } \\
\text { about myself" }\end{array}$ & Emotional/family \\
\hline Family & "Play with kids" & Emotional/family \\
\hline Longevity & "To live longer" & Age \\
\hline Comfort & $\begin{array}{l}\text { "Feel more } \\
\text { comfortable" }\end{array}$ & Physical functioning \\
\hline Look better & $\begin{array}{l}\text { "Look more } \\
\text { beautiful" }\end{array}$ & Appearance \\
\hline
\end{tabular}

\section{Analysis}

We completed dual data entry for all completed surveys into a Research Electronic Data Capture database. ${ }^{22}$ In the analysis we included only patients who (1) answered that their doctor would advise them to lose weight and who wanted to lose weight right now, and (2) had a calculated BMI $\geq 25 \mathrm{~kg} / \mathrm{m}^{2}$. We conducted analyses using SAS software version 9.4 for Windows (SAS Institute Inc., Cary, NC).

We calculated the survey response rate by dividing the number of returned questionnaires by the total number of adult primary care visits during the study periods as reported by the 12 participating practices. We calculated descriptive statistics (proportions and standard deviations) for each variable and the primary outcomes.

To compare the proportion of respondents who reported willingness to participate by the different categories within each variable, we used the $\chi^{2}$ test, with a significance level of $P<.05$, to denote differences. We sought to identify which patient characteristics were independently associated with reported willingness to participate in comprehensive weight loss programs. To identify these patient characteristics, we conducted a logistic regression analysis $(1=$ willing to participate vs $0=$ not willing to participate). We used stepwise logistic regression with age, sex, and race/ethnicity included initially, and then we added additional de- 
scriptive variables (insurance status, BMI, and reported reason for weight loss) that were significantly associated with the primary outcome in the bivariate analysis or that significantly improved the fit of the model. A clinic identifier was included in the final regression model to adjust for clustering of patients by clinic. We converted odds ratios to relative risks (RRs). ${ }^{23}$

\section{Results}

We received 2832 questionnaires from the 12 participating practices (range, 35-817 per site). The response rate across all sites was $29 \%$, with a range of $5 \%$ to $59 \%$. We excluded 15 questionnaires because respondents reported their age as younger than 18 and excluded another 120 because participants did not answer enough questions to interpret the results. Of the remaining 2697 respondents, 1632 reported both that their doctor would advise them to lose weight and that they wanted to lose weight right now. We calculated the BMI of these respondents and excluded those who were underweight $(\mathrm{n}=1)$ or normal weight $(\mathrm{n}=192)$. We included overweight patients (BMI 25 to $<30 \mathrm{~kg}$ / $\mathrm{m}^{2}$ ) in our study because evidence suggests that, similar to obesity, overweight is associated with increased risk of chronic diseases such as diabetes, which can lead to lower health outcomes. ${ }^{9,24}$ The sample size for variables varies from 1362 to 1439 because of differences in missing data for each variable.

The majority of respondents were female $(74.3 \%) ; 32.7 \%$ of all respondents were aged $\geq 55$ years (Table 2). Most respondents identified themselves as non-Hispanic white $(71.6 \%)$, and $7.1 \%$ of respondents identified themselves as American Indian or Alaska native. Only 2.9\% of respondents rated their overall health as excellent, whereas $42.3 \%$ rated their overall health as fair or poor. Of 1439 respondents reporting height and weight, $28.1 \%$ were overweight (BMI $25-29.9 \mathrm{~kg} / \mathrm{m}^{2}$ ), $51.5 \%$ were obese (BMI $30-$ $\left.39.9 \mathrm{~kg} / \mathrm{m}^{2}\right)$, and $20.5 \%$ were extremely obese $\left(\mathrm{BMI} \geq 40 \mathrm{~kg} / \mathrm{m}^{2}\right)$.

We found that $63 \%$ of respondents (907 of 1439) reported willingness to participate in a comprehensive weight loss program as recommended by the USPSTF. Logistical factors such as cost, time of day, and location were commonly identified as important factors in helping people decide whether to participate (Table 3).
Table 2. Descriptive Characteristics of the Respondents

\begin{tabular}{|c|c|}
\hline Characteristic & $\begin{array}{l}\text { Respondents } \\
(\mathrm{N}=1479)\end{array}$ \\
\hline \multicolumn{2}{|l|}{ Age (years) $(\mathrm{n}=1439)$} \\
\hline $18-24$ & 7.9 \\
\hline $25-34$ & 16.5 \\
\hline $35-44$ & 19.3 \\
\hline $45-54$ & 23.7 \\
\hline $55-64$ & 21.7 \\
\hline$\geq 65$ & 11.0 \\
\hline \multicolumn{2}{|l|}{$\operatorname{Sex}(n=1439)$} \\
\hline Male & 25.7 \\
\hline Female & 74.3 \\
\hline \multicolumn{2}{|l|}{ Race/ethnicity ( $\mathrm{n}=1413$ ) } \\
\hline Non-Hispanic white & 71.6 \\
\hline Hispanic or Latino & 7.2 \\
\hline Black or African American & 3.7 \\
\hline Asian & 2.3 \\
\hline Pacific Islander & 1.2 \\
\hline American Indian/Alaska native & 7.1 \\
\hline Some other race & 1.2 \\
\hline Multiple & 7.6 \\
\hline \multicolumn{2}{|l|}{ Insurance status $(\mathrm{n}=1439)$} \\
\hline None & 22.1 \\
\hline Private & 21.1 \\
\hline Medicare & 14.8 \\
\hline Medicaid & 22.1 \\
\hline Military & 20.0 \\
\hline \multicolumn{2}{|l|}{ Overall health $(\mathrm{n}=1431)$} \\
\hline Excellent & 2.9 \\
\hline Very good & 18.0 \\
\hline Good & 36.8 \\
\hline Fair & 31.7 \\
\hline Poor & 10.6 \\
\hline \multicolumn{2}{|l|}{$\mathrm{BMI}(\mathrm{n}=1442)$} \\
\hline Overweight $\left(25-29.9 \mathrm{~kg} / \mathrm{m}^{2}\right)$ & 28.1 \\
\hline Obese $\left(30-39.9 \mathrm{~kg} / \mathrm{m}^{2}\right)$ & 51.5 \\
\hline Extremely obese $\left(\geq 40 \mathrm{~kg} / \mathrm{m}^{2}\right)$ & 20.5 \\
\hline \multicolumn{2}{|c|}{ Reason for wanting to lose weight* $(\mathrm{n}=1362)$} \\
\hline Appearance & 9.9 \\
\hline Emotional/family & 10.7 \\
\hline Physical functioning & 23.0 \\
\hline Medical & 74.6 \\
\hline Age & 1.9 \\
\hline
\end{tabular}

Data are percentages. The sample excludes individuals with missing data for the outcome variable (willingness to participate in comprehensive weight loss program). Sample size varies from 1362 to 1439 because of differences in missing data for each variable.

*Some respondents listed more than one reason for wanting to lose weight.

BMI, body mass index. 
Table 3. Factors That Respondents Reported Were Important in Helping Them Decide Whether to Take Part in a Comprehensive Weight Loss Program $(\mathrm{n}=1479)$

\begin{tabular}{lc}
\hline Factors & $\begin{array}{c}\text { Responses } \\
(\%)\end{array}$ \\
\hline Will help me lose weight & 73.1 \\
Will help me feel better & 55.1 \\
Doesn't cost me much & 54.8 \\
Is at a good time of day for me & 34.0 \\
Is easy to get to & 25.7 \\
Was recommended by my doctor & 15.4 \\
A friend would go with me to the program & 9.6 \\
Was recommended by a friend or family & 2.9 \\
$\quad$ member & \\
\hline
\end{tabular}

Respondents were asked to check the 3 items that are most important to them. The sample excludes individuals with missing data for the outcome variable (willingness to participate in comprehensive weight loss program).

In bivariate analysis, women were more likely than men to report willingness to participate (67.3\% vs $50.8 \% ; P<.001)$ (Table 4$)$. Reported willingness to participate also significantly varied with BMI $(58.8 \%$ for those with BMI 25-29.9 $\mathrm{kg} / \mathrm{m}^{2}, 71.2 \%$ for those with $\mathrm{BMI} \geq 40 \mathrm{~kg} / \mathrm{m}^{2}$; $P<.01)$. Of respondents who reported an emotional reason for weight loss, $73.8 \%$ reported willingness to participate in a comprehensive weight loss program. Of respondents who reported a medical reason for weight loss, $65.5 \%$ reported willingness to participate.

In multivariate analysis (Table 5), women were more likely than men to report willingness to participate (RR, $1.18 ; 95 \%$ confidence interval [CI], 1.07-1.27), and African Americans/blacks (RR, 1.18; 95\% CI, 1.05-1.29) and American Indian/Alaska natives (RR, 1.31; 95\% CI, 1.071.45) were more likely to report willingness to participate compared with non-Hispanic whites. Compared with respondents with private insurance, respondents with Medicare insurance were less likely to report willingness to participate (RR, 0.83; 95\% CI, 0.67-0.99). Reporting an emotional/family reason or reporting a medical reason for weight loss were both associated with an increased willingness to participate (RR, 1.17; 95\% CI, 1.05-1.23 and RR, 1.12; 95\% CI, 1.041.20 , respectively) compared with those not reporting these reasons.

\section{Discussion}

We found that the majority of respondents reported willingness to participate in comprehensive weight loss programs. Ensuring widespread availability of these programs is 1 important step to improve obesity outcomes in the United States. ${ }^{11,25}$ The Patient Protection and Affordable Care Act, which requires insurance companies to provide patients coverage for treatment of obesity, has taken 1 step toward this goal by reducing financial barriers to patient access to evidence-based weight loss treatments. ${ }^{18,19}$ However, not all states have fully adopted insurance reimbursement for obesity treatment: in 2014, only 5 states required coverage of comprehensive weight loss programs as an essential health benefit. ${ }^{26}$ Medicare only reimburses or pays for obesity counseling and treatment provided during in-person, face-to-face visits, further creating potential financial barriers for patient participation in weight loss programs. ${ }^{27}$

The coordinated infrastructure required to implement in-person comprehensive weight loss programs may serve as a barrier to health systems offering these successful programs. Thus it is imperative to consider alternative approaches to providing these programs, such as remote programs delivered through mobile and web support. ${ }^{13,22}$ With the growing adoption of smartphones, testing the effectiveness of mobile health technology-enabled weight loss programs is important because these programs could also address our findings of patient-identified logistical barriers to participation, such as cost, location, and convenience. ${ }^{28}$ These factors were also identified as potential barriers to weight loss program participation in a previous study. ${ }^{29}$

We found that only $15 \%$ of patients cited physician recommendation as an important factor in considering weight loss program participation. While most patients recognized that their physician would advise them to lose weight, our findings underscore the importance of further research to clarify the impact of physician recommendation on patient participation in weight loss programs. Physicians report discomfort with discussing obesity and weight loss with patients, and only a minority of obese adults report having received weight loss counseling from a physician. ${ }^{30-35}$ Motivational interviewing, a counsel- 
Table 4. Reported Willingness to Participate in Comprehensive Weight Loss Program, by Descriptive Characteristics

\begin{tabular}{|c|c|}
\hline Characteristics & $\begin{array}{l}\text { Willing to } \\
\text { Participate (\%) }\end{array}$ \\
\hline Overall $(\mathrm{n}=1439)$ & 63.0 \\
\hline \multicolumn{2}{|l|}{ Age $(\mathrm{n}=1439)(P=.0073)$} \\
\hline $18-24$ & 76.1 \\
\hline $25-34$ & 67.5 \\
\hline $35-44$ & 63.3 \\
\hline $45-54$ & 62.5 \\
\hline $55-64$ & 57.4 \\
\hline$\geq 65$ & 58.9 \\
\hline \multicolumn{2}{|l|}{$\operatorname{Sex}(n=1439)^{*}$} \\
\hline Male & 50.8 \\
\hline Female & 67.3 \\
\hline \multicolumn{2}{|l|}{ Race/ethnicity $(\mathrm{n}=1413)^{*}$} \\
\hline American Indian/Alaska native & 67.7 \\
\hline Asian & 75.8 \\
\hline Black or African American & 80.8 \\
\hline Non-Hispanic white & 59.3 \\
\hline Hispanic or Latino & 74.3 \\
\hline Pacific Islander and other race & 68.874 .7 \\
\hline Multiple & \\
\hline \multicolumn{2}{|l|}{ Insurance status $(\mathrm{n}=1382)(P=.0012)$} \\
\hline None & 65.6 \\
\hline Private & 60.5 \\
\hline Medicare & 54.4 \\
\hline Medicaid & 71.6 \\
\hline Military & 61.2 \\
\hline \multicolumn{2}{|l|}{ Overall health $(\mathrm{n}=1431)$} \\
\hline Excellent & 65.9 \\
\hline Very good & 61.6 \\
\hline Good & 61.9 \\
\hline Fair & 66.1 \\
\hline Poor & 60.3 \\
\hline \multicolumn{2}{|l|}{ BMI $(\mathrm{n}=1442)(P=.0027)$} \\
\hline Overweight (BMI 25-29.9 kg/m²) & 58.8 \\
\hline Obese (BMI 30-39.9 kg/m²) & 62.1 \\
\hline Extremely obese $\left(\mathrm{BMI} \geq 40 \mathrm{~kg} / \mathrm{m}^{2}\right)$ & 71.2 \\
\hline \multicolumn{2}{|l|}{$\begin{array}{l}\text { Reason for wanting to lose weight }{ }^{\dagger} \\
\qquad(\mathrm{n}=1362)\end{array}$} \\
\hline \multicolumn{2}{|l|}{ Appearance } \\
\hline Reason listed & 57.0 \\
\hline Reason not listed & 64.5 \\
\hline \multicolumn{2}{|l|}{ Emotional/family $(P=.0077)$} \\
\hline Reason listed & 73.8 \\
\hline Reason not listed & 62.5 \\
\hline \multicolumn{2}{|l|}{ Physical functioning } \\
\hline Reason listed & 62.3 \\
\hline Reason not listed & 64.2 \\
\hline
\end{tabular}

Continued
Table 4. Continued

\begin{tabular}{lc}
\hline Characteristics & $\begin{array}{c}\text { Willing to } \\
\text { Participate }(\%)\end{array}$ \\
\hline Medical $(P=.0234)$ & \\
$\quad$ Reason listed & 65.5 \\
Reason not listed & 58.7 \\
Age & \\
Reason listed & 76.9 \\
Reason not listed & 63.5 \\
\hline
\end{tabular}

The sample excludes individuals with missing data for the outcome variable (willingness to participate in comprehensive weight loss program). Sample size varies from 1454 to 1545 because of differences in missing data for each variable. ${ }^{*} P<.001$.

${ }^{\dagger}$ Some respondents listed more than one reason for wanting to lose weight.

BMI, body mass index.

ing strategy that allows physicians to work collaboratively with patients to explore and resolve ambivalence related to behavior change, is effective in promoting weight loss. ${ }^{36} \mathrm{Wider}$ adoption of this practice may assist in helping physicians support patients' engagement in comprehensive weight loss programs. ${ }^{37}$

Individual factors, including sex, age, race/ ethnicity, insurance status, and BMI, were all associated with reported willingness to participate in comprehensive weight loss programs. This is consistent with results from clinical trials of weight loss programs, which report differential participant participation and effectiveness based on sex and race/ethnicity. ${ }^{38-41}$ Tailoring referral strategies and comprehensive weight loss programs to specific patient groups may be a useful approach for increasing participation in and the effectiveness of these programs.

We found that patients reported an increased willingness to participate if they cited medical and emotional reasons for weight loss. Physicians leverage patients' motivations to improve medical conditions to engage patients in weight loss programs. Both successful weight loss and maintenance of weight loss are associated with an internal motivation to lose weight. ${ }^{42,43}$ Eliciting patient motivations for weight loss and customizing weight loss programs to patients' motivations may facilitate the successful implementation of weight loss programs in primary care. 
Table 5. Adjusted Relative Risk of Reported Willingness to Participate in a Comprehensive Weight Loss Program, by Patient Characteristics

\begin{tabular}{|c|c|}
\hline Patient Characteristics & $\begin{array}{c}\text { Relative Risk } \\
\text { (95\% CI) }\end{array}$ \\
\hline \multicolumn{2}{|l|}{ Age (years) } \\
\hline $18-24$ & Reference \\
\hline $25-34$ & $0.80(0.64-0.95)$ \\
\hline $45-54$ & $0.77(0.67-0.87)$ \\
\hline $55-64$ & $0.78(0.65-0.91)$ \\
\hline$\geq 65$ & $0.72(0.56-0.89)$ \\
\hline \multicolumn{2}{|l|}{ Sex } \\
\hline Male & Reference \\
\hline Female & $1.18(1.07-1.27)$ \\
\hline \multicolumn{2}{|l|}{ Race/ethnicity } \\
\hline Non-Hispanic white & Reference \\
\hline African American/black & $1.18(1.05-1.29)$ \\
\hline American Indian/Alaska native & $1.31(1.07-1.45)$ \\
\hline Asian & $1.30(1.16-1.40)$ \\
\hline Hispanic/Latino & $1.07(0.86-1.24)$ \\
\hline Pacific Islander/other & $1.12(0.90-1.29)$ \\
\hline Multiple races & $1.21(1.09-1.31)$ \\
\hline \multicolumn{2}{|l|}{ Insurance } \\
\hline Private & Reference \\
\hline None & $0.91(0.80-1.01)$ \\
\hline Medicare & $0.83(0.67-0.99)$ \\
\hline Medicaid & $1.05(0.93-1.16)$ \\
\hline Military & $0.94(0.86-1.22)$ \\
\hline \multicolumn{2}{|l|}{$\mathrm{BMI}$} \\
\hline Overweight (BMI $25-29.9 \mathrm{~kg} / \mathrm{m}^{2}$ ) & Reference \\
\hline Obese (BMI 30-39.9 kg/m²) & $1.05(0.95-1.14)$ \\
\hline Extremely obese $\left(\mathrm{BMI} \geq 40 \mathrm{~kg} / \mathrm{m}^{2}\right)$ & $1.17(0.99-1.31)$ \\
\hline \multicolumn{2}{|l|}{ Reasons for wanting to lose weight } \\
\hline No emotional/family reason & Reference \\
\hline Emotional/family reason & $1.17(1.05-1.23)$ \\
\hline No medical reason & Reference \\
\hline Medical reason & $1.12(1.04-1.20)$ \\
\hline
\end{tabular}

CI, confidence interval; BMI, body mass index.

\section{Limitations}

This study has several limitations. Self-reported height and weight were used to calculate BMI. Adults younger than 30, especially women, may be more likely to underestimate BMI by overestimating height and underestimating weight. ${ }^{44}$ No information was recorded about nonrespondents, and it is possible that clinic staff were more likely to offer the survey to patients they thought would be interested in weight loss programs, potentially biasing our primary outcome toward reported willingness to participate. The majority of study participants were non-Hispanic white and may not be representative of more racially diverse populations. Despite these limitations, we collected and analyzed responses from more than 1500 questionnaires across 12 diverse primary care practices, with $30 \%$ of respondents identifying as nonwhite, improving the generalizability of our findings.

This brief questionnaire asked patients about likely participation in comprehensive weight loss programs, which may not directly correlate with actual participation. In a population-based study, $64 \%$ of adults ( $73 \%$ of women and $55 \%$ of men) reported a desire to lose weight,${ }^{45}$ which is similar to our findings of reported willingness to participate in weight loss programs. Yet, only $48 \%$ of overweight or obese adults report having pursued weight loss in the previous year. ${ }^{45}$ In a large study of patients in a health maintenance organization, only $2.5 \%$ of invited overweight and obese patients participated in an in-person comprehensive weight loss program. Thus rates of program participation may be lower than what respondents reported in this study. ${ }^{46}$ The USPSTF recommendations for comprehensive weight loss programs highlight the need for research to understand effective strategies for dissemination and implementation of these programs. ${ }^{11}$ This research would provide evidence-based pragmatic approaches to increase participation in comprehensive weight loss programs among primary care patients.

\section{Conclusion}

The majority of respondents reported willingness to participate in a comprehensive weight loss program. Delivering programs in ways that address frequently cited barriers to participation, such as cost and convenience, and tailoring recruitment strategies to individual patient characteristics such as sex, race/ethnicity, and BMI, are an important step in addressing the significant problem of overweight and obesity.

The WWAMI Region Practice and Research Network (WPRN) Patient Preferences for Weight Loss in Primary Care Development Group: William Alto, John Holmes, William Kriegsman, Adriana Linares, Alex Reed. The WPRN Patient Preferences for Weight Loss in Primary Care Practice Champions: Sarah Dewane, Kristine Ewing, Debra Gould, Jaime Hornecker, Camille Laudicina, Justin Osborn, Beth Robitaille, Sonja Ronning, Courtney Kennel. 


\section{References}

1. Ogden CL, Carroll MD, Kit BK, Flegal KM. Prevalence of childhood and adult obesity in the United States 2011-2012. JAMA 2014;311:806-14.

2. Ng M, Fleming T, Robinson M, et al. Global, regional, and national prevalence of overweight and obesity in children and adults during 1980-2013: a systematic analysis for the Global Burden of Disease Study 2013. Lancet 2014;384:766-81.

3. Meigs, James B, Wilson PW, Fox CS, et al. Body mass index, metabolic syndrome, and risk of type 2 diabetes or cardiovascular disease. J Clin Endocrinol Metab 2006;91:2906-12.

4. Flegal KM, Graubard BI, Williamson DF, Gail MH. Cause-specific excess deaths associated with underweight, overweight, and obesity. JAMA 2007;298: 2028-37.

5. Gregg EW, Cheng YJ, Cadwell BL, et al. Secular trends in cardiovascular disease risk factors according to body mass index in US adults. JAMA 2005; 293:1868-74.

6. Huisingh-Scheetz MJ, Bilir SP, Rush P, Burnet D, Dale $W$. The independent effect of body mass index on health-related quality of life among racial and ethnic subgroups. Qual Life Res 2013;22:1565-75.

7. Jia H, Lubetkin EI. The impact of obesity on healthrelated quality-of-life in the general adult US population. J Public Health 2005;27:156-64.

8. Luppino FS, de Wit LM, Bouvy PF, et al. Overweight, obesity, and depression: a systematic review and meta-analysis of longitudinal studies. Arch Gen Psychiatry 2010;67:220-9.

9. Must A, Spadano J, Coakley EH, Field AE, Colditz G, Dietz WH. The disease burden associated with overweight and obesity. JAMA 1999;282:1523-9.

10. van Dijk L, Otters HB, Schuit AJ. Moderately overweight and obese patients in general practice: a population based survey. BMC Fam Pract 2006;7:43.

11. Moyer VA. Screening for and management of obesity in adults: US Preventive Services Task Force recommendation statement. Ann Intern Med 2012; 157:373-8.

12. LeBlanc ES, O'Connor E, Whitlock EP, Patnode CD, Kapka T. Effectiveness of primary care-relevant treatments for obesity in adults: a systematic evidence review for the US Preventive Services Task Force. Ann Intern Med 2011;155:434-47.

13. Appel LJ, Clark JM, Yeh H, et al. Comparative effectiveness of weight-loss interventions in clinical practice. N Engl J Med 2001;365:1959-68.

14. Franz MJ, VanWormer JJ, Crain AL, et al. Weightloss outcomes: a systematic review and meta-analysis of weight-loss clinical trials with a minimum 1-year follow-up. J Am Diet Assoc 2007;107:1755-67.

15. Hickman IJ, Jonsson JR, Prins JB, et al. Modest weight loss and physical activity in overweight patients with chronic liver disease results in sustained improvements in alanine aminotransferase, fasting insulin, and quality of life. Gut 2004;53:413-9.

16. Tate DF, Jackvony EH, Wing RR. Effects of Internet behavioral counseling on weight loss in adults at risk for type 2 diabetes: a randomized trial. JAMA 2003;289:1833-6.

17. Wing RR, Lang $W$, Wadden TA, et al. Benefits of modest weight loss in improving cardiovascular risk factors in overweight and obese individuals with type 2 diabetes. Diabetes Care 2011;34:1481-6.

18. Koh HK, Sebelius KG. Promoting prevention through the Affordable Care Act. N Engl J Med 2010;363:1296-9.

19. Madison K, Schmidt H, Volpp KG. Smoking, obesity, health insurance, and health incentives in the Affordable Care Act. JAMA 2013;310:143-4.

20. US Census Bureau. Race. Available from: http:// www.census.gov/topics/population/race/about.html. Accessed April 14, 2015.

21. National Heart, Lung, and Blood Institute. Classification of overweight and obesity by BMI, waist circumference, and associated disease risks. Available from: https://www.nhlbi.nih.gov/health/educational/ lose_wt/BMI/bmi_dis.htm. Accessed June 19, 2015.

22. Hamar B, Coberley C, Pope JE, Rula EY. Initial evaluation of a scalable lifestyle program for sustained weight loss. J Obes Weight Loss Ther 2014; S4:005.

23. Zhang J, Yu KF. What's the relative risk? A method of correcting the odds ratio in cohort studies of common outcomes. JAMA 1998;280:1690-1.

24. Field AE, Coakley EH, Must A, et al. Impact of overweight on the risk of developing common chronic diseases during a 10-year period. Arch Intern Med 2001;161:1581-6.

25. Ogden CL, Carroll MD, Kit BK, Flegal KM. Prevalence of obesity among adults: United States, 20112012. NCHS Data Brief 2013;131:1-8.

26. Weiner J, Colameco C; University of Pennsylvania Leonard Davis Institute of Health Economics; Robert Wood Johnson Foundation. Essential health benefits: 50 -state variations on a theme. Available from: http://www.rwjf.org/content/dam/farm/reports/ issue_briefs/2014/rwjf416179. Accessed April 16, 2016.

27. Centers for Medicare and Medicaid Services. Decision Memo for Intensive Behavioral Therapy for Obesity. Available from: https://www.cms.gov/ medicare-coverage-database/details/nca-decisionmemo.aspx? \&NcaName = Intensive \% 20Behavioral $\% 20$ Therapy $\% 20$ for $\% 20$ Obesity \&bc =ACAAAAAA IAAA\&NCAId=253\&. Accessed March 22, 2016.

28. Smith A. U.S. smartphone use in 2015. Washington, DC: Pew Research Center; 2015. Available from: http://www.pewinternet.org/2015/04/01/us-smartphone-use-in-2015. Accessed April 1, 2015.

29. Jensen MD, Ryan DH, Apovian CM, et al. 2013 AHA/ACC/TOS guideline for the management of overweight and obesity in adults: a report of the 
American College of Cardiology/American Heart Association Task Force on Practice Guidelines and the Obesity Society. J Am Coll Cardiol 2014;63: 2985-3023.

30. Epling JW, Morley CP, Ploutz-Snyder R. Family physician attitudes in managing obesity: a cross-sectional survey study. BMC Res Notes 2011;4:473.

31. Felix H, West DS, Bursac Z. Impact of USPSTF practice guidelines on clinician weight loss counseling as reported by obese patients. Prev Med 2008; 47:394-7.

32. Galuska DA, Will JC, Serdula MK, Ford ES. Are health care professionals advising obese patients to lose weight? JAMA 1999;282:1576-8.

33. Huang J, Yu H, Marin E, Brock S, Carden D, Davis T. Physicians' weight loss counseling in two public hospital primary care clinics. Acad Med 2004;79: 156-61.

34. Ko JY, Brown DR, Galuska DA, Zhang J, Blanck HM, Ainsworth BE. Weight loss advice US obese adults receive from health care professionals. Prev Med 2008;47:587-92.

35. Shiffman S, Sweeney CT, Pillitteri JL, Sembower MA, Harkins AM, Wadden TA. Weight management advice: what do doctors recommend to their patients? Prev Med 2009;49:482-6.

36. Rollnick S, Miller WR, Butler CC, Aloia MS. Motivational interviewing in health care: helping patients change behavior. COPD 2008;5:203.

37. Armstrong MJ, Mottershead TA, Ronksley PE, Sigal RJ, Campbell TS, Hemmelgarn BR. Motivational interviewing to improve weight loss in overweight and/or obese patients: a systematic review and metaanalysis of randomized controlled trials. Obes Rev 2011;12:709-23.
38. Wing RR, Hamman RF, Bray GA, et al; Diabetes Prevention Program Research Group. Achieving weight and activity goals among diabetes prevention program lifestyle participants. Obes Res 2004;12: $1426-34$.

39. Wadden TA, West DS, Neiberg RH, et al. One-year weight losses in the Look AHEAD Study: factors associated with success. Obesity 2009;17:713-22.

40. Wadden TA, Neiberg RH, Wing RR, et al. Fouryear weight losses in the Look AHEAD Study: factors associated with long-term success. Obesity 2011;19:1987-98.

41. West DS, Elaine Prewitt T, Bursac Z, Felix HC. Weight loss of black, white, and Hispanic men and women in the Diabetes Prevention Program. Obesity 2008;16:1413-20.

42. Elfhag K, Rössner S. Who succeeds in maintaining weight loss? A conceptual review of factors associated with weight loss maintenance and weight regain. Obes Rev 2005;6:67-85.

43. Williams GC, Grow VM, Freedman ZR, Ryan RM, Deci EL. Motivational predictors of weight loss and weight-loss maintenance. J Pers Soc Psychol 1996; 70:115-26.

44. Gorber SC, Tremblay M, Moher D, Gorber B. A comparison of direct vs. self-report measures for assessing height, weight and body mass index: a systematic review. Obes Rev 2007;8:307-26.

45. Yaemsiri S, Slining MM, Agarwal SK. Perceived weight status, overweight diagnosis, and weight control among US adults: the NHANES 2003-2008 Study. Int J Obes 2011;35:1063-70.

46. Glasgow RE, Nelson CC, Kearney KA, et al. Reach, engagement, and retention in an Internet-based weight loss program in a multi-site randomized controlled trial. J Med Internet Res 2007;9:e11. 